\title{
Process Parameter Optimization for Abrasive Water Jet Machining of Titanium Alloy Using Meta-Heuristic Algorithms
}

\author{
Vishal S Sharma ${ }^{1}$, Amit Kumar², Munish Kumar Gupta ${ }^{3}$, Neeraj Bhanot ${ }^{4}$ \\ 1\&2I \& P Deptt., Dr. B.R. Ambedkar NIT Jalandhar, Punjab, India \\ ${ }^{3} M E D, L C E T$, Ludhiana, INDIA \\ ${ }^{4}$ Department of Quantitative methods and Operation Management, Indian Institute of Management, Amritsar, Punjab, India \\ Address correspondence to Vishal S Sharma, sharmavs@nitj.ac.in
}

\begin{abstract}
Recently, the trend of optimization algorithms for improvements of surface quality and productivity characteristics in abrasive water jet machining of titanium alloy (Ti-6Al-4V alloy) has become increasingly more widespread in various industrial sectors i.e., aircraft and automobile Industries. Here, the present research attempts to select the ideal or best AWJM process parameters by implementing the well known meta-heuristic algorithm i.e., Teacher learning based optimization method (TLBO). The AWJM experiments as per the Taguchi L9 orthogonal array were performed on $\mathrm{Ti} 6 \mathrm{Al}-4 \mathrm{~V}$ titanium alloy by considering jet transverse speed, stand-off distance and abrasive flow as the input parameters. Then, the influence of process parameters on surface roughness and material removal rate has been performed by means plot and ANOVA analysis. After that, the results are optimized with the TLBO method. The overall results indicate that the TLBO method is an efficient method used to find the optimal results with very short interval of time i.e., within $3 \mathrm{sec}$.
\end{abstract}

\section{INTRODUCTION}

Abrasive water jet machining (AWJM) is a modern trend of cutting solution that is largely implemented in the machining of difficult-to-cut materials such as nickel and titanium based alloys [1]. The cutting action in AWJM takes place due to the erosion action of high velocity abrasive particles along with the jet of water, respectively. The AWJM process expresses the major advantages such as no contact tool that might break during machining, less heat-affected zone and low cutting forces in various industrial applications [2]. However, the involvement of large process parameters such as jet traverse speed, standoff distance and abrasive flow rate makes the AWJM performance difficult at large scale application [3]. Therefore, the optimization of AWJM process parameters is an emerging solution for drastically improvement performance in terms of surface quality and productivity[2]. The optimization of process parameters have been performed in two manners i.e., single response optimization and multi-response optimization. In the context of single response optimization, the Taguchi based $\mathrm{S} / \mathrm{N}$ ratio analysis has been successfully implemented around the world in various applications such as machining, rapid prototyping, material processing etc [4-6]. However, the Taguchi method is not preferred where more than one response or process parameter has been involved. Therefore, to tackle this situation, the implementation of multi-response optimization is a fruitful option and provides a very useful result for practical applications of process.

In the recent years, several research efforts have been made on multi-response optimization of process parameters by implementing different methods such as response surface methodology, desirability approach, multi-criteria decision methods and meta-heuristic algorithms such as particle swarm optimization, genetic algorithm, teacher learning based optimization etc [7-11]. In the first work, Lan performed the optimization of turning parameters by using TOPSIS and Taguchi methods [12]. Secondly, Gauri et al. successfully applied the TOPSIS method for determine the optimal parameters setting in ultrasonic process [13]. Similarly, the application of PSO in micro-machining of medical devices is reported by Vazquez et a.l [14]. On same context, Ciurana et al. used the ANN model integrated with PSO for obtaining the ideal parameters in pulsed laser micromachining for hardened AISI H13 steel [15]. Likewise, Ulutan and Ozel implemented the physics based simulation model of PSO for prediction of responses during turning of nickel alloys [16]. In another work, the optimization of grinding process parameters using PSO has been carried by Pawar et al. [17].

From the current literature, it has been interestingly noticed that the trend of multi-response optimization of 
process parameters by using discussed method is currently a hot topic of research. However, it has been observed that the implementation of these optimization methods in AWJM of process parameters using metaheuristic algorithms is still not reported in literature. Therefore, this study expresses the first attempt to investigate the multi-response optimization of AWJM process parameters in mostly used $\mathrm{Ti}-6 \mathrm{Al}-4 \mathrm{~V}$ titanium alloy using teacher learning based meta-heuristic algorithm, respectively. In this regard, the range of AWJM process parameters i.e., jet traverse speed, standoff distance and abrasive flow have been carefully selected and the optimization of surface roughness and material removal rate have been performed. Thereafter, the effect of process parameters on quality and productivity characteristics has been investigated by $\mathrm{S} / \mathrm{N}$ ratio plots. In the end, the optimization is performed by subjected algorithm.

\section{MATERIALS AND METHODS}

\subsection{Workpiece material}

The AWJM experiments were performed on mostly used grade of titanium alloy i.e., Ti-6Al-4V alloy (size: $575 \mathrm{~mm} \times 55 \mathrm{~m} \times 12 \mathrm{~mm}$; hardness: $35 \mathrm{HRC}$ ), shown in Figure 1. It is also known as the "workhorse" of the titanium industry because it is by far the most common $\mathrm{Ti}$ alloy, accounting for more than $50 \%$ of total titanium usage. Besides, this is referred as a poor machinability material due to its various inherent characteristics such as low thermal conductivity, high work hardening capability and chemical affinity etc. The chemical composition of used Ti-6Al-4V alloy is presented in Table 1.

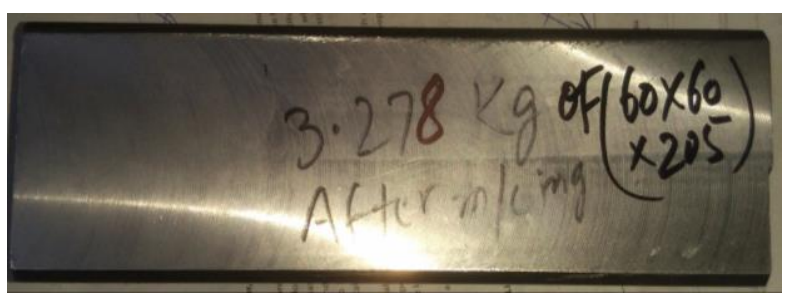

Fig. 1. Workpiece material i.e., Ti-6Al-4V titanium alloy

Table 1. The compositional range for Ti $6 \mathrm{Al}-\mathrm{V} 4$ alloy

\begin{tabular}{|l|l|}
\hline $\begin{array}{l}\text { Carbon (Maximum) } \\
0.10 \%\end{array}$ & Titanium Balance \\
\hline Aluminum 5.50 to $6.75 \%$ & Vanadium 3.50 to $4.50 \%$ \\
\hline Nitrogen $0.05 \%$ & Iron (Maximum) $0.40 \%$ \\
\hline Oxygen (Maximum) & Hydrogen (Maximum) \\
$0.020 \%$ Total (Maximum) & \\
\hline $\begin{array}{l}\text { Other, To \% } \\
0.40 \%\end{array}$ & \\
\hline
\end{tabular}

The OMAX Jet Machining centre (model no 2652, shown in Figure 2), a precision abrasive jet machining has been used for performing the experimental runs. The AWJM tool is operated under specific software control and able to cut complex parts out of most materials including metal, plastic, glass, ceramics, stone and composites using standard CAD drawing files. The machine has X-Y motion system, high-pressure plumbing and swivels, a high-pressure nozzle, and an abrasive feed system (hopper).

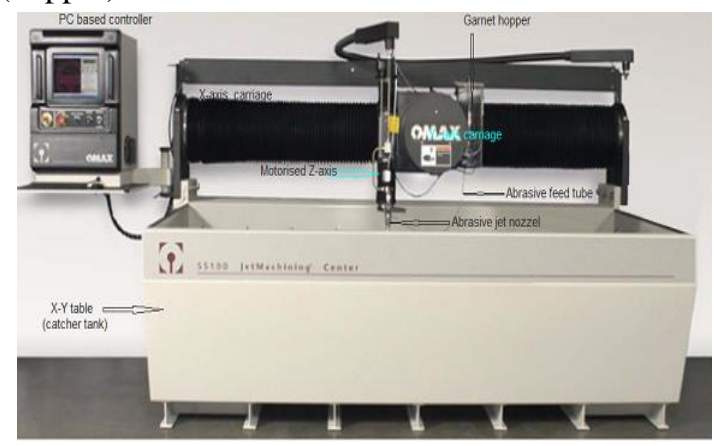

Fig. 2. Abrasive Water Jet Machining Centre

\subsection{Measurement of responses}

The present work consists of two output responses i.e., surface roughness and material removal rate. For measurement of surface roughness values, the Surtronic S-100 Series portable roughness tester has been used. The average surface roughness parameter $(\mathrm{Ra})$ is selected for experimental readings. Similarly, for material removal rate, the mass of work pieces were measured before and after the trials. Then, the time of experiment was recorded from the machine and thus MRR (gram/min) was calculated after dividing the difference of mass (gram) by time (minutes).

\subsection{Design of Experiments}

In order to efficiently perform the experiments, the Taguchi L9 orthogonal array design has been selected. The three different process parameters at three levels i.e., pressure (levels: 1500, 2000, 2500 Bar), stand of distance (SOD) (level: 1.5, 2, $2.5 \mathrm{~mm}$ ), Jet Transverse Speed (JTS) (level: 40, 50, $60 \mathrm{~mm} / \mathrm{min}$ ) are selected as input values and combinations are varied in conformance with the L9 orthogonal array, as furnished in Table 2 and 3 . The other important parameters that were kept constant during tests are Abrasive Flow Rate $(0.356 \mathrm{Kg} / \mathrm{min})$, jet impact angle at neutral nozzle position $\left(90^{\circ}\right)$, orifice diameter $(0.3556$ $\mathrm{mm})$, nozzle length $(76.2 \mathrm{~mm})$, nozzle diameter $(0.762$ $\mathrm{mm}$ ), abrasive material ( 80 mesh garnet particles with the density of $4100 \mathrm{~kg} / \mathrm{m} 3$ ) and average diameter of abrasive particles $(0.18 \mathrm{~mm})$. The garnet consists of chemically $36 \% \mathrm{FeO}, 33 \% \mathrm{SiO} 2,20 \% \mathrm{Al} 2 \mathrm{O} 3,4 \% \mathrm{MgO}, 3 \% \mathrm{TiO} 2$, $2 \% \mathrm{CaO}$ and $2 \% \mathrm{MnO} 2$.

\subsection{Abrasive water jet machining centre}


Table 2. List of parameters and their levels

\begin{tabular}{|l|l|l|l|}
\hline Factors & Level 1 & Level 2 & Level 3 \\
\hline Pressure (bar) & 1500 & 2000 & 2500 \\
\hline $\begin{array}{l}\text { Jet Transverse } \\
\text { Speed } \\
\text { (mm/min) }\end{array}$ & 40 & 50 & 60 \\
\hline $\begin{array}{l}\text { Stand-off } \\
\text { distance (mm) }\end{array}$ & 1.5 & 2.0 & 2.5 \\
\hline
\end{tabular}

Table 3. Experimental results

\begin{tabular}{|c|c|c|c|c|}
\hline \multicolumn{3}{|c|}{ Input Parameters } & \multicolumn{2}{c|}{ Output Parameters } \\
\hline $\begin{array}{c}\text { Pressure } \\
\text { (bar) }\end{array}$ & $\begin{array}{c}\text { Jet } \\
\text { Transverse } \\
\text { Speed } \\
(\mathbf{m m} / \mathbf{m i n})\end{array}$ & $\begin{array}{c}\text { Stand- } \\
\text { off } \\
\text { distance } \\
(\mathbf{m m})\end{array}$ & $\begin{array}{c}\text { Material } \\
\text { Removal } \\
\text { Rate } \\
\left(\mathbf{c m}^{3}\right. \\
\mathbf{m m i n}^{3}\end{array}$ & $\begin{array}{c}\text { Surface } \\
\text { Roughness } \\
(\boldsymbol{\mu m})\end{array}$ \\
\hline 1500 & 40 & 1.5 & 1.352182 & 2.100 \\
\hline 1500 & 50 & 2 & 1.589574 & 2.075 \\
\hline 1500 & 60 & 2.5 & 1.817500 & 2.300 \\
\hline 2000 & 40 & 2 & 1.433636 & 2.250 \\
\hline 2000 & 50 & 2.5 & 1.651333 & 2.067 \\
\hline 2000 & 60 & 1.5 & 1.980418 & 2.000 \\
\hline 2500 & 40 & 2.5 & 1.442000 & 2.100 \\
\hline 2500 & 50 & 1.5 & 1.658889 & 2.125 \\
\hline 2500 & 60 & 2 & 1.908355 & 1.800 \\
\hline
\end{tabular}

\section{RESULTS AND DISCUSSIONS}

In this section, firstly the influence of process parameters on surface roughness and material removal rate has been analyzed. After that, the multi-response optimization has been performed by the TLBO method. Lastly, the confirmation runs were executed to confirm the validity of meta-heuristic algorithm.

\subsection{Influence on surface roughness}

In order to check the statistical significance of each individual process parameter, initially the analysis of variance (ANOVA) test has been applied on the experimental data. The analysis of variance (ANOVA) test for surface roughness ( $\mathrm{Ra}$ ) is shown in Table 3 . It is evident that, Jet transverse speed alone influences $\mathrm{Ra}$ significantly. Since the F - Value of Jet transverse speed is 1.54 and having percentage contribution of $54.53 \%$, therefore this parameter is considered to be most significant for Ra. Further, the main effect for means are successfully plotted to study the influence of each factor on surface roughness values, as shown in Figure 3. It has been remarkably seen that the values of surface roughness increases with the change in pressure (1500 to 2000) and transverse speed (40 to 60). Besides, the standoff distance shows the opposite results as compare with the pressure and jet transverse speed. The surface roughness values initially increases by changing the values of stand-off distance 1.5 to 2.0 and decreases with change in stand-off distance from 2.0 to 2.5.

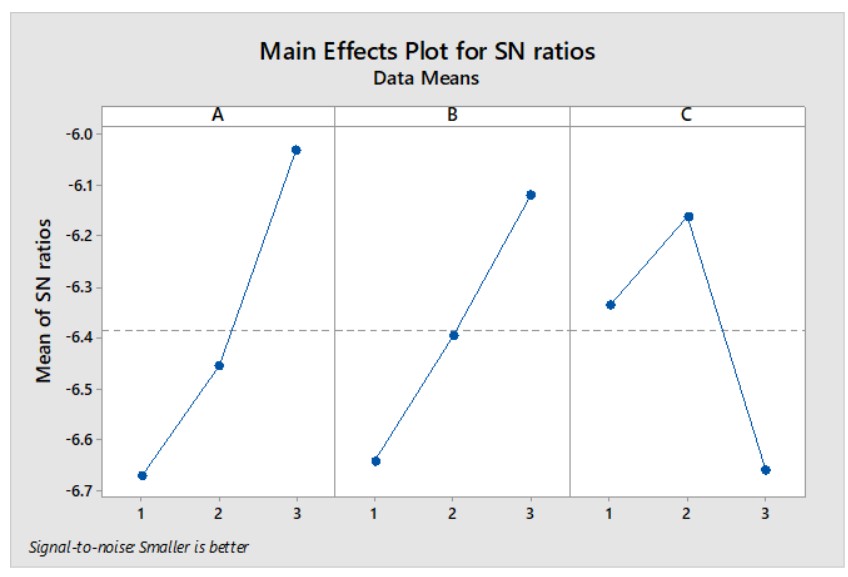

Fig. 3. Main effect plots for surface roughness values * A- Pressure, B- Jet Traverse Speed (JTS), C- Stand Off Distance (SOD)

Table 4. ANOVA for $\mathrm{SR}\left(\mathrm{R}_{\mathrm{a}}\right)$

\begin{tabular}{|c|c|c|c|c|c|}
\hline Source & DF & Adj SS & Adj MS & F-Value & $\%$ \\
\hline Pressure & 2 & 0.03474 & 0.01737 & 0.39 & 21.17 \\
\hline JTS & 2 & 0.08835 & 0.01022 & 1.54 & 54.53 \\
\hline SOD & 2 & 0.02057 & 0.01029 & 0.23 & 13.05 \\
\hline Error & 2 & 0.02034 & 0.04417 & & \\
\hline Total & 8 & 0.16409 & & & \\
\hline
\end{tabular}

\subsection{Influence on material removal rate}

The ANOVA for MRR is shown in Table 5. It is evident that Jet transverse speed alone has very dominating effect on MRR. Since the F - Value of Jet transverse speed is 160.97 and having percentage contributions as $84.32 \%$, therefore this parameter is considered to be most significant for MRR. Furthermore, the main effect plot for MRR has been shown in Figure 4. It has been observed from the main effect plots that the material removal rate is increases with the pressure from 1500 to 2500 and jet transverse speed from 40 to 60, respectively. On the other hand, the material removal rate decreases with change in stand-off distance from 1.5 to 2.5. This is attributed to the scientific reason that the increase in pressure and jet transverse speed increases the velocity of carrier gas that conveying the abrasive particles, hence more material is removed from the workpiece. On the contrary, increase in stand-off distance at certain point reduces MRR because of the reduced taper in the machined groove and kerf width, respectively. 


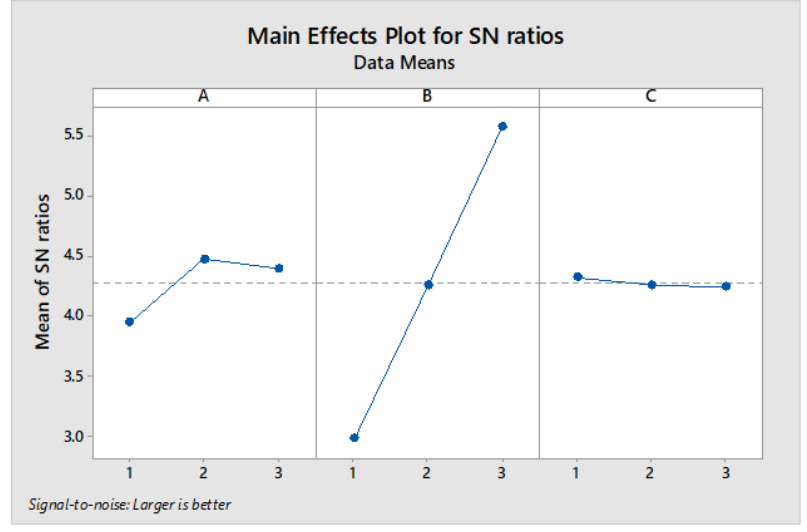

Fig. 4. Main effect plots for material removal rate values * A- Pressure, B- Jet Traverse Speed (JTS), C- Stand Off Distance (SOD)

Table 5. ANOVA for MRR

\begin{tabular}{|c|c|c|c|c|c|}
\hline Source & DF & Adj SS & Adj MS & F-Value & $\%$ \\
\hline Pressure & 2 & 0.017707 & 0.008853 & 7.80 & 4.58 \\
\hline JTS & 2 & 0.365310 & 0.182655 & 160.97 & 84.32 \\
\hline SOD & 2 & 0.001170 & 0.000585 & 0.52 & $3.01 \%$ \\
\hline Error & 2 & 0.002269 & 0.001135 & & \\
\hline Total & 8 & 0.386456 & & & \\
\hline
\end{tabular}

\subsection{Multi-response optimization of process} parameters using meta-heuristic algorithm

In the current work, the well known meta-heuristic algorithm i.e., teacher learning based optimization (TLBO) method has been selected to perform the multiresponse optimization [18]. The TLBO algorithm, originally developed by R.V. Rao, is successfully implemented to solve the constrained and unconstrained optimization problem in different areas [19]. They also compared the efficiency of TLBO algorithm with other methods of optimization. It was reported that, the TLBO algorithm provides better results over several evolutionary techniques in less number of iterations. The algorithm does not require any specific algorithm control parameters. The boundary conditions for the parameters are collected from the Table 2. The detailed information and the implementation procedure are deeply discussed elsewhere.

Working of TLBO: To achieve the desired goal, the AWJM process parameters with respect to the surface roughness and material removal rate has been optimized in this part. For this purpose, initially a combined objective is generated (as given by Equation (1)) and the multi-response optimization is performed for the combined objective.

$$
\operatorname{Max} \text { C.O. }=W_{1}{ }^{*}(R a / R a \min )-W_{2}{ }^{*}(M R R / M R R \max )
$$

Where, W1 and W2 are the weights (i.e., 0.5 each) given to the surface roughness and MRR values. Then, the regression equation of combined objective function is established for TLBO fitness function, as given in Equation 2.
C.O $=0.776-0.000026 \quad$ Pressure +0.00464 Jet Transverse Speed $\quad+0.0156$ Standoff Distance

Further, to find out the optimum values, the algorithm are executed a number of times. Table 6 presents the optimal solution along with the best, worst and average readings using TLBO method. Similarly, Figure 5 shows the convergence characteristics graph of obtained optimal results. It has been observed that the success rate of TLBO method is $95 \%$ and convergence time is only 3 seconds for each iteration. This is because there is no specific parameters are used for proper function the algorithm.

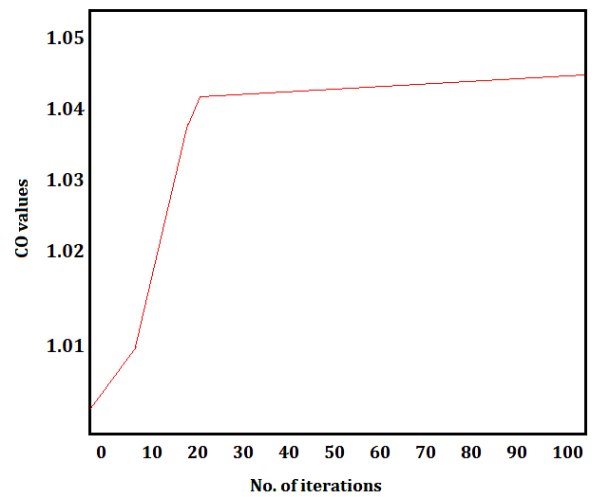

Fig. 5. Convergence characteristics plots for $\mathrm{CO}$ values

\subsection{Confirmatory experiments}

This is the final step usually performed to check the validity or adequacy of the developed optimization models. The obtained AWJM optimal parameters are given as: 1500 bar pressure, $60 \mathrm{~mm} / \mathrm{min}$ jet transverse speed and $1.5 \mathrm{~mm}$ stand-off distance, respectively. It has been obtained that the experimental values obtained at these optimal setting show very close relation with each other. The error below 5\% confirmed that the metaheuristic algorithms i.e., TLBO shows very promising results in terms of AWJM process parameters. Hence, the TLBO is an effective and time saving optimization methods used for determining the ideal conditions.

Table 6. Optimized parameters for maximization of $\mathrm{CO}$ value

\begin{tabular}{|c|c|}
\hline Parameters & TLBO \\
\hline Pressure (bar) & 1500 \\
\hline Jet Transverse Speed (mm/min) & 60 \\
\hline Stand-off distance & 1.5 \\
\hline Best Solution & 1.04425 \\
\hline Average & 1.03426 \\
\hline Worst & 1.02436 \\
\hline Average time (sec) & 4.32 \\
\hline Confirmatorv experiments & 1.04536 \\
\hline Error & $4.32 \%$ \\
\hline
\end{tabular}




\section{CONCLUSIONS}

This research presents the experimental investigation complimented with the surface quality and productivity optimization in AWJM of Ti-6Al-4V titanium alloy. The following conclusions can be drawn for effective machining of Ti $6 \mathrm{Al} 4 \mathrm{~V}$ by AWJM process as follows:

- From the optimization results, the success rate of TLBO method is $95 \%$ and convergence time is only 3 seconds for each iteration.

- The ANOVA analysis showed a high degree of fit with respect to the high correlation value.

- From the ANOVA analysis, jet transverse speed (JTS) plays a major role on influencing material removable rate (MRR) by $84.32 \%$ as observed in ANOVA F test.

- In case of Surface roughness, jet transverse speed plays major significance of about $54.53 \%$. Stand-off distance is having least significance influence on SR.

- The obtained AWJM optimal parameters are given as: $1500 \mathrm{bar}$ pressure, $60 \mathrm{~mm} / \mathrm{min}$ jet transverse speed and $1.5 \mathrm{~mm}$ stand-off distance, respectively.

\section{References}

1. Sasikumar KSK, Arulshri KP, Ponappa K, Uthayakumar M (2016) A study on kerf characteristics of hybrid aluminium 7075 metal matrix composites machined using abrasive water jet machining technology. Proc Inst Mech Eng Part B J Eng Manuf 232:690-704. doi: $10.1177 / 0954405416654085$

2. Jagadish, Bhowmik S, Ray A (2015) Prediction of surface roughness quality of green abrasive water jet machining: a soft computing approach. J Intell Manuf 1-15. doi: 10.1007/s10845-015-1169-7

3. Chaturvedi V, Singh D (2015) Multi Response Optimization of Process Parameters of Abrasive Water Jet Machining for Stainless Steel AISI 304 Using VIKOR Approach Coupled with Signal to Noise Ratio Methodology. J Adv Manuf Syst 14:107-121. doi: 10.1142/S0219686715500080

4. Gupta MK (2015) Optimization of machining parameters for turning AISI 4340 steel using Taguchi based grey relational analysis. Indian J Eng Mater Sci 22:679-685.

5. Gupta MK, Singh G, Sood PK (2015) Modelling and Optimization of Tool Wear in Machining of EN24 Steel Using Taguchi Approach. J Inst Eng Ser C 96:269-277. doi: 10.1007/s40032-015-0175-Z

6. Biswas SA, Datta S, Bhaumik S, Majumdar G (2009) MULTI-RESPONSE OPTIMIZATION : A CASE STUDY IN. 2009:26-28.

7. Thakur DG, Ramamoorthy B, Vijayaraghavan L (2009) Optimization of Minimum Quantity Lubrication Parameters in High Speed Turning of Superalloy Inconel 718 for Sustainable Development. World Acad Sci Eng Technol 54:224-226.
8. Neşeli S, Yaldız S, Türkeş E (2011) Optimization of tool geometry parameters for turning operations based on the response surface methodology. Measurement 44:580-587. doi: http://dx.doi.org/10.1016/j.measurement.2010.11.018

9. Guodong L, Yong L, Quancun K, Hao T (2016) Selection and Optimization of Electrolyte for Micro Electrochemical Machining on Stainless Steel 304. Procedia CIRP 42:412-417. doi: 10.1016/j.procir.2016.02.223

10. Yildiz AR, Öztürk F (2010) Hybrid TaguchiHarmony Search Approach for Shape Optimization. In: Geem ZW (ed) Recent Adv. Harmon. Search Algorithm. Springer Berlin Heidelberg, Berlin, Heidelberg, pp 89-98

11. Gupta MK, Sood PK, Sharma VS (2016) Optimization of machining parameters and cutting fluids during nano-fluid based minimum quantity lubrication turning of titanium alloy by using evolutionary techniques. J Clean Prod 135:12761288. doi: 10.1016/j.jclepro.2016.06.184

12. Lan T-S (2009) Taguchi optimization of multiobjective CNC machining using TOPSIS. Inf Technol J 8:917-922.

13. Gauri SK, Chakravorty R, Chakraborty S (2011) Optimization of correlated multiple responses of ultrasonic machining (USM) process. Int $\mathrm{J} \mathrm{Adv}$ Manuf Technol 53:1115-1127. doi: 10.1007/s00170010-2905-y

14. Vazquez E, Ciurana J, Rodríguez CA, et al. (2011) Swarm intelligent selection and optimization of machining system parameters for microchannel fabrication in medical devices. Mater Manuf Process 26:403-414.

15. Ciurana J, Arias G, Ozel T (2009) Neural network modeling and particle swarm optimization (PSO) of process parameters in pulsed laser micromachining of hardened AISI H13 steel. Mater Manuf Process 24:358-368.

16. Ulutan D, Özel T (2013) Multiobjective optimization of experimental and simulated residual stresses in turning of nickel-alloy IN100. Mater Manuf Process 28:835-841.

17. Pawar PJ, Rao R V, Davim JP (2010) Multiobjective optimization of grinding process parameters using particle swarm optimization algorithm. Mater Manuf Process 25:424-431.

18. Venkata Rao R, Kalyankar VD (2013) Parameter optimization of modern machining processes using teaching-learning-based optimization algorithm. Eng Appl Artif Intell 26:524-531. doi: 10.1016/j.engappai.2012.06.007

19. Venkata Rao R, Kalyankar VD (2011) Parameter Optimization of Machining Processes Using a New Optimization Algorithm. Mater Manuf Process 27:978-985. doi: 10.1080/10426914.2011.602792. 